\title{
Road map unveiled to tackle neglected diseases
}

The WHO hopes to control or eliminate ten diseases by 2020.

\section{Daniel Cressey}

30 January 2012

The World Health Organization today laid out plans to control or eliminate a swathe of diseases that predominantly affect the world's poorest people. To tackle neglected tropical diseases, as they are known, it is bringing together national governments, the pharmaceutical industry and philanthropists.

The initiative includes plans for a major expansion of programmes in which industry donates drugs for the treatment of such diseases, including Chagas disease, visceral leishmaniasis (also known as kala azar) and river blindness. The pharmaceutical industry, meanwhile, has pledged to increase cooperation to expedite the hunt for new treatments.

Neglected tropical diseases (NTDs) are estimated to affect more than one billion people worldwide, but because most of these people are in poor, rural areas of the developing world they have generally attracted little in the way of research efforts to

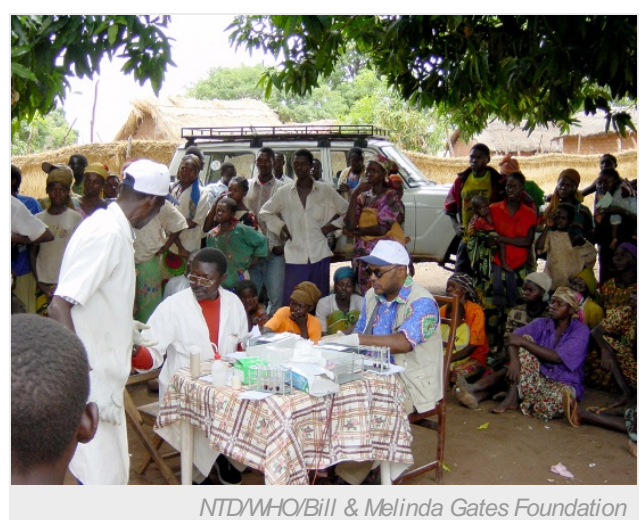

Mobile teams of health-care workers can screen for diseases such as sleeping sickness, which is fatal if left untreated. find cures, or supply of treatments that already exist.

This has already started to change. In 2009, the Bill \& Melinda Gates Foundation announced a US\$34-million grant to boost work on these NTDs (see: Neglected disease boost).

At a meeting in London today, Margaret Chan, the director-general of the World Health Organization (WHO), presented the group's 'road map' for dealing with 17 neglected diseases in a co-coordinated effort with 13 drug companies, the Bill \& Melinda Gates Foundation, and others.

\section{Coordinated action}

The WHO is focusing on drug treatments along with disease management, control of disease vectors and non-human hosts, veterinary public health, and improvements in sanitation and drinking water. The road map identifies 17 diseases, 10 of which the organization believes can be eliminated or controlled by 2020 (see Box).

It is, says Chan, the "most comprehensive, coordinated action" ever to address NTDs. "I've never seen so many competitors working together," she told the meeting.

\author{
Diseases the WHO hopes to eliminate or control by 2020 \\ Guinea worm \\ Lymphatic filariasis \\ Blinding trachoma \\ Sleeping sickness \\ Leprosy \\ Soil-transmitted helminthes \\ Schistosomiasis \\ River blindness \\ Chagas disease \\ Visceral leishmaniasis
}

The Gates Foundation announced the largest chunk of additional funding so far: a five-year, \$363-million donation for research 
relating to NTDs, including new treatments and delivery.

"What's unique about today is getting everybody on the same page," said Bill Gates. He added that, given the scope of the new commitments, "maybe, as the decade goes on, people will wonder if these should be called neglected diseases".

Drug companies in attendance announced expansions and extensions to many current efforts that supply free or at-cost drugs for NTDs. The combination of new and existing donations amounts to 1.4 billion treatments a year.

However, the charity Médecins Sans Frontières (also known as Doctors Without Borders) said that challenges in the area were being "glossed over" in the new road map. The emphasis on donations from pharmaceutical companies could mean that strategies are influenced by what products are made available rather than what is actually required for good public health.

"Expanded drug donations from the pharmaceutical industry will be part of the solution, but it is not possible to eliminate and control diseases such as Chagas, kala azar or sleeping sickness without increased support for programmes to identify and treat patients, and increased investment for new and better diagnostic tests and medicines," said Daniel Berman, deputy director of Médecins Sans Frontières' campaign for access to essential medicines, in a statement.

\section{Compound collaboration}

Eleven companies, including AstraZeneca, GlaxoSmithKline, Sanofi and Bristol-Myers Squibb, are expanding their sharing of intellectual property on various diseases. They are either already working with or are negotiating agreements with the non-profit Drugs for Neglected Diseases Initiative. This work will share compounds in an effort to speed up the development of therapies, and follows similar moves to tackle malaria (see GlaxoSmithKline goes public with malaria data).

"Sharing libraries of compounds is extraordinarily difficult," said Christopher Viehbacher, chief executive of Paris-based Sanofi. "It's only because of the unmet need we've been able to get together. We're starting to work together in partnership in an unprecedented way."

Andrew Witty, chief executive of GlaxoSmithKline, headquartered in London, said that the opening up of compound libraries would ensure that the next generation of NTD treatments would be developed.

"What we've seen over the last year or so is a real coming together of industry." he told the London meeting.

Witty cited an African proverb that states that if you want to travel fast you should travel alone, but if you want to travel far you should travel in a group. "The industry wants to travel far," he said.

Nature I doi:10.1038/nature.2012.9938 